\title{
The Effect of Organizational Culture on Organizational Commitment for Participants in Leadership Education and Training Level IV of the Ministry of Finance
}

\author{
Suradi
}

Widyaiswara Madya at the Magelang Leadership Education and Training Center, Education and Training Center for Human Resource Development, Financial Education and Training Agency, Ministry of Finance, Indonesia

http://dx.doi.org/10.18415/ijmmu.v6i5.1147

\begin{abstract}
Organizational culture can be the main competitive advantage instrument and employee commitment since they tend to be affected by organizational culture aspects at work. This research discusses the effect of organizational culture on employee organizational commitment. The research objective is to analyze how the effect of organizational culture on organizational commitment through three dimensions consisting of affective commitment, continuance commitment and normative commitment. The research sample involved 130 people from echelon IV officials who were attending the Leadership Education and Training Level IV of the Ministry of Finance using a saturated sampling technique in which all members of the population became research samples. This research employed causality model or relationship or effect. To test the proposed hypothesis, it utilized SEM (Structural Equation Models) analysis techniques. Based on statistical results, organizational culture has a positive and significant effect on organizational commitment. This is evidenced from the results of the $p$ (probability) value of $0.07>0.05$ and an estimated value of 0.75 which shows a positive result. It means that if the culture of the organization increases, it will affect the increase in organizational commitment.
\end{abstract}

Keywords: Organizational Culture; Organizational Commitment ; Human Resources

\section{Introduction}

There is a lot of research that has been conducted on the effect of organizational culture on organizational commitment. For instance, research conducted by Padma and Nair (2009) shows that there is a positive effect of organizational culture on organizational commitment. Shoaib et al (2013) investigated the effect of organizational culture on organizational commitment. Organizational culture has a significant effect on three dimensions of organizational commitment. They conduct research related to the effect of organizational culture on organizational commitment to private companies and public organizations.

Based on previous studies, researchers modified variables that affect organizational commitment to find out whether organizational culture, as stated by Denison, also affects organizational commitment 
to participants in Leadership Education and Training Level IV at the Magelang Education and Leadership Training Center in the 2017 fiscal year. The author conducted this research using the organizational commitment questionnaire through various adjustments as stated (Allen and Meyer, 1990).

The government has a role that determines the success of a good state administration which is carried out together with other stakeholders such as the business world and society. To carry out this role, it requires the State Civil Apparatus (ASN) which has the competency standards required by their respective positions indicated by having extensive knowledge and insight and always following the latest developments in their field of work, as well as having values, attitudes, and behavior which is full of loyalty and obedience to the state, has good moral and mentality, is neutral, is aware of its responsibilities as a public servant, and is able to become a pioneer of national unity and integrity.

To achieve excellent service, it requires state administrators who have high commitment in implementing the vision and mission of government organizations. Through this commitment, the work ethic for each individual will emerge in the organization which will build the organizational culture. Organizational culture has become an important theme in management and business research over the past few decades due to its potential to affect the set of outcomes desired by organizations and individuals such as commitment, loyalty, turnover, and job satisfaction (Chow et al, 2001). This commitment can be realized if individuals in the organization are aware of their rights and obligations in the organization without seeing the position and level of each individual because the achievement of organizational goals is the result of the collective cooperation of all members of the organization. Nongo and Ikyanyon (2012) stated that organizational culture is a very important factor for an organization to achieve a goal.

A number of studies in the private and public sectors have confirmed that organizational culture can affect organizational commitment and organizational performance (Saeed and Hassan, 2015). According to Messner (2013) organizational culture is the key to understanding and affecting organizational commitment. Organizational culture has a very important role in efforts to achieve organizational goals. Organizational culture is important because it is the habits that occur in the organizational hierarchy that represent the norms of behavior that members of the organization follow. Culture also has an important function for the organization. Organizational culture is a system of spreading trust and values that develop in an organization and direct the behavior of members of the organization. Organizational culture can be the main competitive advantage instrument if organizational culture supports organizational strategy and if organizational culture can answer or overcome environmental challenges quickly and appropriately.

Porter et al (2003) define organizational commitment as an identifiable relative strength and individual involvement in a particular organization where it is indicated by a strong belief in the goals and values of the organization, a willingness to make certain efforts for the interests of the organization and a strong desire to continue to be a member of the organization. Based on Steers and Porter's explanation, organizational commitment is needed to maintain the continuity and consistency of the implementation of good state governance, especially in providing good services to the community. According to Angle and Perry (1993), organizational commitment is a form of social contract between employees and organizations to which employees will respond to the benefits provided by the organization.

Employee commitment to the organization, where employees tend to be affected by organizational culture aspects, attracts the researcher to conduct research on the participants of Leadership Education and Training Level IV of the Ministry of Finance to find out whether organizational culture also affects organizational commitment as the results of previous studies. 


\section{Research Method}

\section{Research Time and Setting}

The research setting and period are as follows:

- Research Setting

The research setting is the Magelang Leadership Education and Training Center where Leadership Education and Training Level IV within the Ministry of Finance for the 2017 fiscal year is held.

- Research Period

The research period is September to December 2017.

\section{Research Design}

This research applies an ex post facto research design. Ex post facto research aims to find the causes that allow changes in behavior, symptoms or phenomena caused by an event, behavior or things that cause changes in the independent variables that have overall occurred (Widarto, 2013). Ex post facto definitions are after facts; i.e., research conducted after an event occurs. Ex post facto research aims to find causes that allow changes in behavior, symptoms or phenomena caused by an event, behavior, symptoms or phenomena caused by an event, behavior or things that cause changes in the overall independent variable has already occurred.

This research aims to test and analyze the effect of organizational culture on organizational commitment of participants in Leadership Education and Training Level IV of the Ministry of Finance in the 2017 fiscal year. The approach used in this analysis is a quantitative approach. It means that the measurement of quantitative data and objective statistics through scientific calculations comes from a sample of people or residents who are asked to answer a number of questions about the survey to determine the frequency and percentage of their responses. Since the end result is numeric and is included in the category of circumstance words, it is called a quantitative approach.

\section{Data Type and Source}

The research approach used in this research is a quantitative approach that refers to theories related to organizational culture and organizational commitment. The definition of a quantitative approach is the measurement of quantitative data and objective statistics through scientific calculations derived from a sample of people or residents who are asked to answer a number of questions about the survey to determine the frequency and percentage of their responses. Primary data in this study were obtained through the distribution of questionnaires conducted to participants in Leadership Education and Training Level IV of the Ministry of Finance in the 2017 fiscal year.

\section{Population and Sample}

The research population are all participants Leadership Education and Training Level IV in the 2017 Leadership Education and Training Center in the 2017 budget year of 163 people. Since the population is not too large (163 people), this research will use the census method.

\section{Research Instrument}

The research instrument is a tool used to measure natural and social phenomena that are being observed. Specifically, all of these phenomena are called research variables (Sugiyono, 2010). 
Data collected for use in this research were divided into two groups consisting of primary data and secondary data. Primary data collection is carried out in the following ways:

a. Questionnaire: it is carried out by distributing questionnaire containing a set of statements that logically affects the research variables in which each statement is the answers that have meaning to test the hypothesis.

b. Meanwhile, secondary data collection is carried out through literature studies obtained from various sources such as books, journals, research findings, articles, magazines and so on. The instrument used to measure the research variables will be tested for validity and reliability. The research instrument in the form of a questionnaire was first tested for validity and reliability to ensure that the research instrument could measure what should be measured.

\section{Validity Test and Reliability Test Validity Test}

Validity test is intended to test research instruments so that they can provide results in accordance with the stated objectives. A questionnaire can be declared valid if the statement in the questionnaire is able to measure something that will be measured by the questionnaire. Validity test aims to measure whether the statements that have been made in the questionnaire can measure what will be measured. Validity testing in this research was carried out through data homogeneity test by finding the correlation between the scores of each statement item with the total score (Pearson correlation). Sugiyono (2010) states that "if the developed theory is correct, then the measurement results using measuring instruments based on the theory are already seen as valid results".

\section{Convergent Validity in Modeling}

Convergent means to center. In this case, it is intended to describe the relationship of measuring devices that measure the same attributes. Instruments that measure the same attributes are expected to have a high score correlation. It is expected that the correlation score between the instruments is higher than the correlation with other instruments. Initially, the above understanding means the composite score of an instrument. However, recent developments indicate that item scores are also used. It is assumed that between one item and another item on the same instrument is a different method that measures the same attribute. This method is called convergent validity.

\section{Discriminant Validity}

Discriminant validity refers to the degree of discrepancy between attributes that should not be measured by the measuring instrument and theoretical concepts about the variable. Discriminant validity of the reflexive measurement model can be calculated based on the cross-loading value of the manifest variable against each latent variable. If the correlation between the latent variable and each indicator (manifest variable) is greater than the correlation with the other latent variable, the latent variable is considered to predict the indicator better than the other latent variable.

In addition, discriminant validity can also be calculated by comparing the square root of average variance extracted (AVE) values. If $\sqrt{A V E}$ value is higher than the correlation value between latent variables, then discriminant validity can be considered achieved. Discriminant validity can be considered to be achieved if the AVE value is greater than 0.5. 


\section{Reliability Test}

According to Nazir (2014) reliability concerns the accuracy of measuring instruments. Reliability is a tool to measure the consistency of a questionnaire which is an indicator of research variables. A questionnaire is considered reliable if a person's answer to a statement is consistent or stable from time to time. Reliability test is used to test the extent to which the results of a measurement can be trusted. Reliability is related to the degree of consistency/ constancy of the data in a certain time interval. Instruments that have good reliability can be used to measure many times and produce the same data (consistent). According to Sugiyono (2010), reliability is the extent to which the results of measurements using the same object will produce the same data. The boundary value used to assess an acceptable level of reliability is 0.70 even though it is not a "fixed" measure. It means that if the research conducted is exploratory, a value below 0.70 is still acceptable as long as it is accompanied by empirical reasons that are seen in the exploration process (Ferdinand, 2015).

\section{Data Analysis Technique}

Research requires a data analysis and interpretation that will be used to answer research questions to reveal certain phenomena. Thus, data analysis is the process of simplifying data in a form that is easier to read and interpret. The model that will be used in this study is a model of causality or relationship or effect. In addition, to test the proposed hypothesis, the analysis technique used is SEM (Structural Equation Models).

The use of SEM analysis method can identify the dimensions of a construct and at the same time be able to measure the effect or degree of relationship between factors whose dimensions have been identified (Ferdinand, 2015). A complete SEM modeling basically consists of measurement model and structural model. Measurement model is intended to confirm a dimension or factor based on its empirical indicators.

\section{Results and Discussion}

\section{Organizational Culture Variable}

The statistical description of organizational culture variables in this research consists of four indicators. The four indicators consist of (1) involvement, (2) consistency, (3) adaptability, and (4) mission. Statistical descriptions of responses for each indicator can be seen in Table 1 below:

Table 1. Statistical Description of Organizational Culture Variable

\begin{tabular}{|l|l|l|l|l|}
\hline Indicators & Minimum & Maximum & Mean & Std. Deviation \\
\hline Involvement $\left(\mathrm{X}_{1}\right)$ & 2.00 & 5.00 & 4.0026 & 0.54035 \\
Consistency $\left(\mathrm{X}_{2}\right)$ & 2.33 & 5.00 & 4.2538 & 0.52958 \\
Adaptability $\left(\mathrm{X}_{3}\right)$ & 2.67 & 5.00 & 4.2590 & 0.51884 \\
Mission $\left(\mathrm{X}_{4}\right)$ & 2.50 & 5.00 & 4.4000 & 0.55125 \\
\hline Average & 2.00 & 5.00 & 4.2288 & \\
\hline
\end{tabular}

Based on Table 1, the summary of respondents' responses to organizational culture variable has a good average rating above 4.0000 (maximum of 5.000) for each indicator. The highest score is found on 
the adaptability indicator $\left(\mathrm{X}_{3}\right)$ of 4.2590 . This shows that the adaptability indicator is the most appropriate in describing organizational culture variable. Overall, the average value of the indicator is 4.2288 (good).

\section{Organizational Commitment Variable}

The statistical description of the organizational commitment variable in this research consists of three indicators. The three indicators consist of (1) affective, (2) continuance, and (3) normative. Statistical descriptions for each indicator can be seen in Table 2 below:

Table 2. Statistical Description of Organizational Commitment Variable

\begin{tabular}{|l|l|l|l|l|}
\hline Indicators & Minimum & Maximum & Mean & Std. Deviation \\
\hline Affective & 2.86 & 5.00 & 4.2412 & .60696 \\
Continuance & 1.38 & 5.00 & 3.7471 & .84068 \\
Normative & 2.25 & 4.88 & 3.5221 & .47655 \\
\hline Average & 1.38 & 5 & 3.8368 & \\
\hline
\end{tabular}

Based on Table 2, the summary of respondents' answers (indicators) to the organizational commitment variable has a good and sufficient average rating category. The biggest score is the affective indicator (Y1) of 4.2412. This shows that affective indicator is relevant in describing organizational commitment. The overall average value of the indicator is 3.8368 (relatively good).

\section{Confirmatory Factor Analysis of Exogenous Variable}

The exogenous variable of organizational culture is built on four indicators. The four indicators consist of (1) involvement, (2) consistency, (3) adaptability, and (4) mission. The results of the confirmatory factor analysis of organizational culture variables can be seen in the output of the analysis using the Lisrel program below.

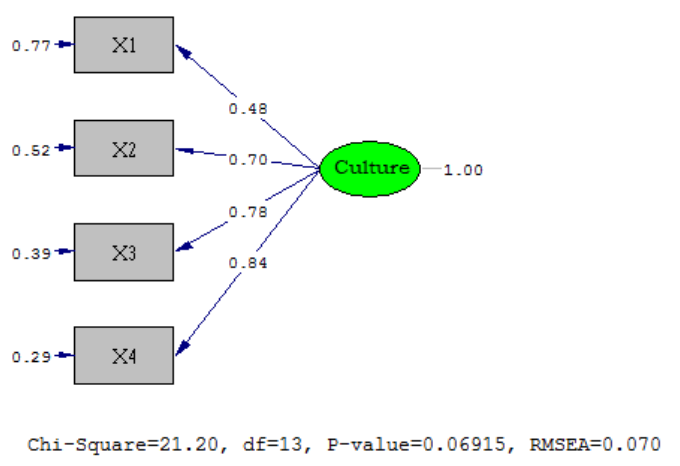

Figure 1. Confirmatory Analysis Result of Exogenous Variable

The results of the confirmatory analysis are explained through the following equation:

- $\mathrm{X}_{1}=0.48$ Culture +0.77

- $\mathrm{X}_{2}=0.70$ Culture +0.52

- $\mathrm{X}_{3}=0.78$ Culture +0.39

- $\mathrm{X}_{4}=0.84$ Culture +0.29 
The above model shows the relationship between each indicator forming the organizational culture variable that every increase of culture by 1 unit will be followed by an increase in $\mathrm{X}_{1}$ of $0.48, \mathrm{X}_{2}$ of $0.70, \mathrm{X}_{3}$ of 0.78 , and $\mathrm{X}_{4}$ of 0.84 . Indicator $\mathrm{X} 4$ with a loading factor level of 0.84 indicates that this indicator has a more dominant role than other indicators in shaping organizational culture variables.

The loading factor results above can be used to measure construct validity where a questionnaire is considered to be valid if the questions on the questionnaire are able to reveal something that is measured by the questionnaire. According to Hair et al (2010), the minimum number of factor loading is $>0.5$ or ideally $>0.7$. So, it can be concluded that all questions used to measure organizational culture can be declared valid.

\section{Confirmatory Factor Analysis of Endogenous Variable}

The organizational commitment variable in the research was constructed using three indicators. The three indicators consist of (1) affective, (2) continuance, and (3) normative. The results of the confirmatory factor analysis of organizational commitment variables can be seen in the analysis output using the Lisrel program below.

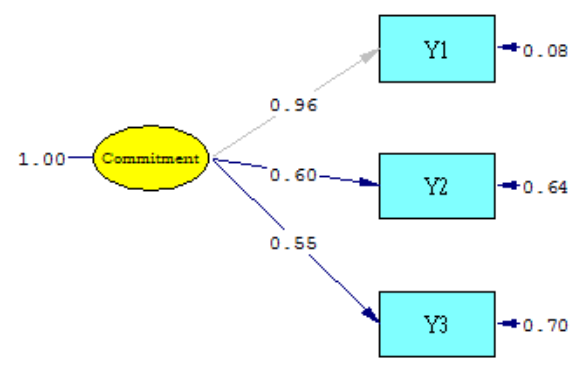

Figure 2. Confirmatory Analysis Result of Endogenous Variable

The result of the confirmatory analysis of the latent variable of organizational commitment (commitment) is explained through the following equation:

- $\mathrm{Y}_{1}=0.96$ Commitment +0.08

- $\mathrm{Y}_{2}=0.60$ Commitment +0.64

- $\mathrm{Y}_{3}=0.55$ Commitment +0.70

The above model shows the relationship between each indicator forming the organizational commitment variable that each commitment increase of 1 unit will be followed by an increase in $\mathrm{Y}_{1}$ of $0.96, \mathrm{Y}_{2}$ of 0.60 , and $\mathrm{Y}_{3}$ of 0.55 . Affective Indicator $(\mathrm{Y} 1)$ with a loading factor level of 0.96 indicates that this indicator has a more dominant role than other indicators in constructing organizational commitment variables. Furthermore, the result of loading factor above is $>0.5$. Thus, it was concluded that all questions used to measure organizational commitment were declared valid.

\section{Analysis of Structural Equation Modeling (SEM)}

This analysis is used to determine the structural relationship between the variables under research. Structural relationships that occur between variables can be tested for compatibility through the goodness of fit index. The results of SEM analysis in this research can be seen in Figure 6 below: 


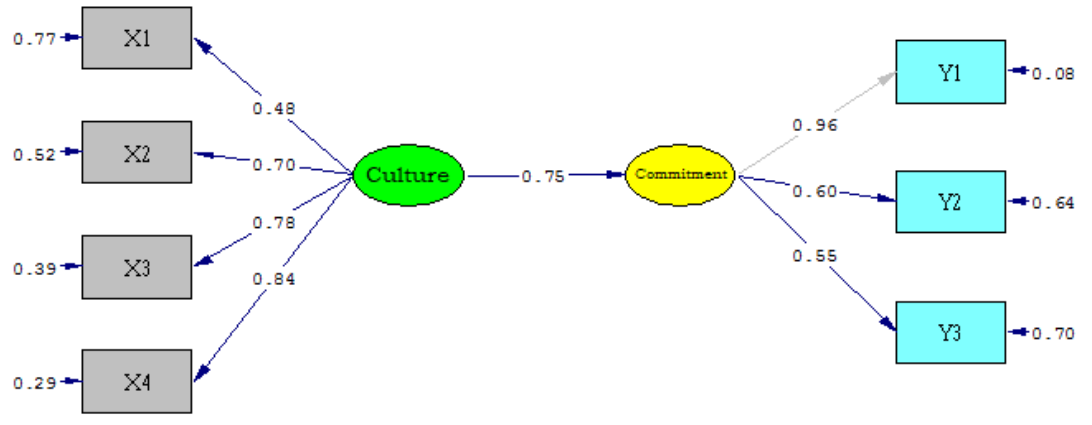

Chi-Square $=21.20, \mathrm{df}=13, \mathrm{P}-\mathrm{value}=0.06915, \mathrm{RMSEA}=0.070$

Figure 3. Test Results of Full Structural Equation Modeling (SEM) Model table below:

Based on the above Figure 3, the Goodness of Fit value of the full SEM model can be seen in the

Table 3. Full Model Goodness of Fit SEM Test

\begin{tabular}{|l|l|l|l|}
\hline Goodness of Index & Cut-off Value & Result of the Model & Description \\
\hline Chi Square & Expected to be small & 21.20 & Good \\
\hline Probability & 0.05 & 0.06915 & Good \\
\hline RMSEA & $<0.08$ & 0.070 & Good \\
\hline GFI & $>0.90$ & 0.96 & Good \\
\hline AGFI & 0.90 & 0.90 & Marginal \\
\hline CFI & 0.95 & 0.98 & Good \\
\hline
\end{tabular}

Source: Processing results

According to Table 3 above, the chi square value is 21.20 with a probability of $0.0692>0.05$, an RMSEA value of $0.070<0.08$, a GFI value of $0.96>0.90$, an AGFI value of $0.90>0.90$, and a CFI value of $0.98>0.95$, which indicates that the goodness of fit test can be well received. Thus, this research concludes that the structure of modeling analysis can be carried out. Based on the path analysis in Figure 3 , it obtained the structural model as follows: $\mathrm{Y}=0.72 \mathrm{X}+0.44$

\section{SEM Assumption Testing Data Normality}

The next test is to see the normality level of the data used in this research. This test is carried out by observing the value of the skewness data when the $\mathrm{CR}$ value in the skewness data is in the range between +2.58 or at the 0.01 significance level. The data normality test results are shown in Table 3 . The above output (Table 4) shows the results of the data normality test in the "Test of Multivariate Normality for Continuous Variables" row. The results of the normality test can be identified through the p-value of skewness and kurtosis indicators which indicate the value $>0.05$, so that the research variables can be considered to have passed the normality test. 
Table 4. Normality Test

\begin{tabular}{|l|l|l|l|l|l|l|}
\hline \multirow{2}{*}{ Variables } & \multicolumn{3}{|l|}{ Skewness } & Kurtosis & \multicolumn{2}{l|}{ Skewness and Kurtosis } \\
\cline { 2 - 7 } & Z-Score & P-Value & Z-Score & P-Value & Chi-Square & P-Value \\
\hline $\mathrm{X}_{1}$ & -0.185 & 0.853 & -0.414 & 0.679 & 0.206 & 0.902 \\
\hline $\mathrm{X}_{2}$ & -0.819 & 0.413 & -1.071 & 0.284 & 1.817 & 0.403 \\
\hline $\mathrm{X}_{3}$ & -0.695 & 0.487 & -0.936 & 0.349 & 1.358 & 0.507 \\
\hline $\mathrm{X}_{4}$ & -1.667 & 0.095 & -1.711 & 0.087 & 5.709 & 0.058 \\
\hline
\end{tabular}

\section{Reliability and Variance Extract Test}

The reliability test shows the extent to which a measuring instrument can provide relatively the same results if measurements are taken again on the same object. The minimum reliability value of the latent variable forming dimensions that can be accepted is 0.60 . The following formula is used to obtain the value of the level of reliability of the dimensions of the latent variable:

\section{Construct Reliability $=\frac{(\Sigma \text { Standard Loading })^{2}}{(\Sigma \text { Standard Loading })^{2}+\Sigma \dot{E} j}$}

Description:

- Standard loading is obtained from standardized loading for each indicator obtained from the Lisrel calculation results

- $\quad \Sigma \dot{\mathrm{E} j}$ is the measurement error for each indicator. Measurement error can be obtained from 1 (standard loading) $)^{2}$

To analyze the results of this reliability test, the above equation is presented in the form of a table to calculate the reliability level of the indicators (dimensions) of each variable. From this table, the reliability of the four constructs of latent variables is obtained and the one used in this research is one that has a reliability higher than 0.6. Thus, the construct gauges have quite high reliability. The measurement of variance extract shows the amount of variance of the indicator extracted by the developed construct/ latent variable. The acceptable variance extract value is a minimum of 0.40 . The equation to obtain the variance extract value is:

\section{Variance Extract $=\frac{\left(\Sigma \text { Standard Loading }^{2}\right)}{\left(\Sigma \text { Standard Loading }{ }^{2}\right)+\Sigma \text { Éj }}$}

To assess the level of variance extract of each latent variable, the above equation is outlined in a tabular form showing the results of data processing. The results of data processing reliability and variance extract are shown in Table 5.

The results of reliability testing and variance extract on each latent variable on the dimensions of its formation indicate that all variables show a reliable measure because each has a reliability greater than 0.6 .

Table 5. Reliability and Variance Extract Results

\begin{tabular}{|l|l|l|}
\hline Variables & Reliability & Variance Extract \\
\hline Organizational Culture & 0.933 & 0.784 \\
\hline Organizational Commitment & 0.867 & 0.702 \\
\hline
\end{tabular}


The variance extract test results have also shown that each latent variable is the result of a fairly large extraction of its dimensions. This is indicated by the variance extract value of each variable with a value of more than 0.4 .

\section{Hypothesis Testing}

Hypothesis testing is carried out to determine whether or not the independent variable affects the dependent variable. Previously, the effect of exogenous variables on endogenous variables can be seen from the figure below:

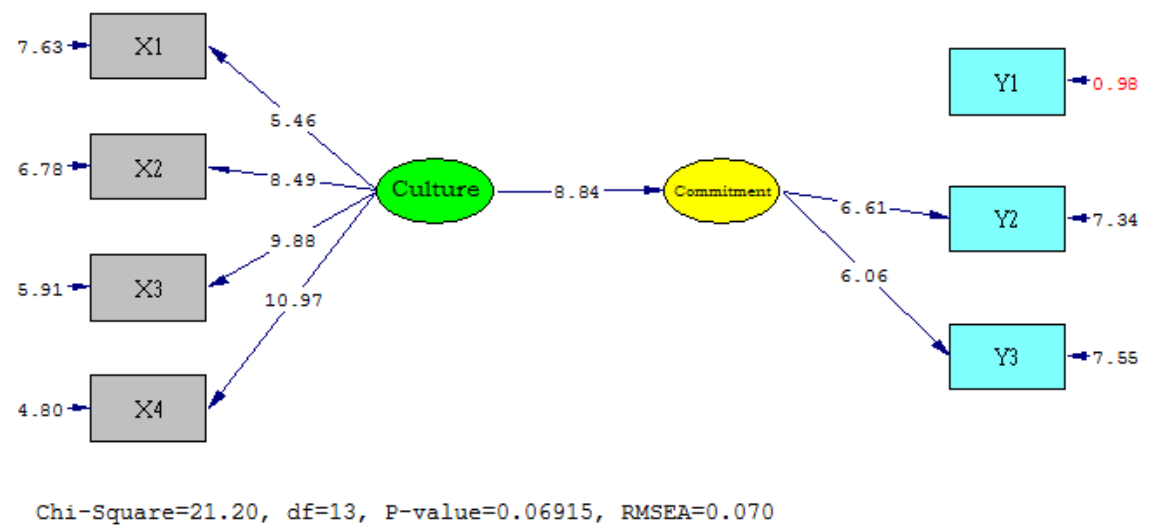

Figure 4. Hypothesis Test Results of Structural Equation Modeling (SEM) Model

The hypothesis is accepted if the probability $(\mathrm{p})$ value $<0.05(\mathrm{t}$ table $=1.96)$. Based on the above figure, $\mathrm{t}$ count $=8.84>1.96$ so that organizational culture variable significantly affects organizational commitment.

\section{Conclusion}

Based on statistical results, organizational culture has a positive and significant effect on organizational commitment. This is evidenced from the results of the $\mathrm{p}$ (probability) value of $0.07>0.05$ and an estimated value of 0.75 which shows a positive result. It means that if the organizational culture increases, it will affect the increase in organizational commitment.

The results of this research are consistent with research conducted by Padma and Nair (2009) and Shoaib et al (2013) which proves the positive effect of organizational culture on organizational commitment. Thus, increasing organizational commitment can be carried out through improving organizational culture by increasing mission indicator. In addition, increasing mission indicator is reflected in the establishment of a clear organization and implementation of the organization's vision and mission.

\section{Suggestion}

This research still examines limited problems. Therefore, further research is suggested to develop a model that is formed by exploring more broadly the variables that can affect organizational commitment so that it can contribute more to employee performance, especially in the Ministry of Finance. 


\section{References}

Allen, N. J., \& Meyer, J. P. (1990). The measurement and antecedents of affective, continuance and normative commitment to the organization. Journal of occupational psychology, 63(1), 1-18.

Angle, H., \& Perry, J. (1983). Organizational commitment: individual and organizational influences. Work and Occuptaion Volume 10: 123 - 146.

Augusty, F. (2002). Structural equation modeling dalam penelitian manajemen. Semarang: Fakultas Ekonomi Universitas Diponegoro, 143.

Chow, C. W, Harrison, G.L, Mckinnon J. L., \& Wu, A. (2001). Organisational culture: Association with affective commitment, job satisfaction, propensity to remain and information sharing in a Chinese cultural context. CIBER working paper. San Diego State Univerisity.

Hair, J. F., Black, W. C., Babin, B. J., \& Anderson, R. E. (2013). Multivariate data analysis: Pearson new international edition. Pearson Higher Ed.

Messner, W. (2013). Effect of organizational culture on employee commitment in the Indian IT services sourcing industry. Journal of Indian Business Research, 5(2), 76-100.

Nazir, M. (2014). Metode Penelitian. Cetakan Kesembilan. Jakarta: Ghalia Indonesia.

Nongo, E. S., \& Ikyanyon, D. N. (2012). The Influence of Corporate Culture on Employee Commitment to the Organization. International Journal of Business and Management;7(22).

Padma, R. N., \& Nair, V. S. (2009). Organizational Culture and its Impact on Organizational Commitment in Public and Private Organizations. Global Management Review, 4(1).

Porter, L. W., Bigley, G. A., \& Steers, R. M. (2003). Motivation and work behavior. New York: McGraw-Hill International Edition.

Saeed, M., \& Hassan, M. (2015). Organizational culture and work outcomes: Evidence from some Malaya.

Shoaib, A., Zainab, R., Maqsood, H. \& Sana, R. (2013). Impact of Organizational Culture on Organizational Commitment: A Comparative Study of Public and Private Organizations. Research Journal of Recent Sciences, 2(5), 15-20.

Sugiyono. (2010). Metode Penelitian Kuantitatif, Kualitatif, dan R\&D. Bandung: CV Alfabeta.

Widarto, M. P. (2013). Penelitian Ex Post Facto. Disampaikan pada kgiatan Pelatihan Metodologi Penelitian Pendidikan di Fakultas Teknik, Universitas Negeri Yogjakarta tanggal 27 S.D. 28 Juni 2013.

\section{Copyrights}

Copyright for this article is retained by the author(s), with first publication rights granted to the journal.

This is an open-access article distributed under the terms and conditions of the Creative Commons Attribution license (http://creativecommons.org/licenses/by/4.0/). 